\title{
Knowledge, Attitude and Practices of Contraceptive Methods in Women of Reproductive Age Group in an Urban District of Haryana
}

\author{
Sanjana Dawra', Sarita Goyal ${ }^{2 *}$, Mahesh Chander Gupta ${ }^{3}$ \\ ${ }^{1}$ Junior Resident, Department of Pharmacology, Pt. B.D. Sharma, Post Graduate Institute of Medical Sciences, Rohtak \\ (Haryana), India \\ ${ }^{2}$ Associate Professor, Department of Pharmacology, Pt. B.D. Sharma, Post Graduate Institute of Medical Sciences, Rohtak \\ (Haryana), India \\ ${ }^{3}$ Senior Professor and Head, Department of Pharmacology, Pt. B.D. Sharma, Post Graduate Institute of Medical Sciences, \\ Rohtak (Haryana), India
}

*Address for Correspondence: Dr. Sarita Goyal, Associate Professor, Department of Pharmacology, Pt. B.D. Sharma, PGIMS Rohtak, Haryana 124001, India

E-mail: drsaritagoyal@rediffmail.com

Received: 08 Jul 2019/ Revised: 19 Sep 2019/ Accepted: 14 Dec 2019

\begin{abstract}
Background: India ranks $2^{\text {nd }}$ amongst the world's most populous countries with a birth rate of 19 births/1000 population and is projected to attain the first position by 2024, surpassing the population of China. Awareness regarding contraceptive practices can have multiple health and economic benefits.

Methods: This was a cross-sectional questionnaire-based study, done among 260 women between the age group of 18-50 years, who was questioned by a pre-set proforma, which included the details of knowledge, attitude, and practice regarding contraceptive use.

Results: Mean age of the study participants was 26.3 years. Around $97.69 \%$ of women had heard about contraception. The most common contraceptive used i.e. condom $38.07 \%$, followed by pills (24.61\%) and IUDs (13.64\%). Implants, diaphragms, female condoms were the least practiced methods of contraception. Maximum women (71.53\%) had gained knowledge regarding contraception through TV, radio or newspapers. Almost every working woman was aware of contraception and around $95 \%$ of housewives had heard of contraceptive practices. $42.85 \%$ and $18.26 \%$ housewives and working women, respectively felt the awkwardness in asking about contraceptives. More than $70 \%$ of working women believed in encouraging their family members regarding contraceptive practices, followed by housewives.

Conclusion: Occupation was an important factor related to the adoption and understanding of the concept of family planning in the population. There should be increased counseling of couples as well as the family members, regarding contraceptive methods, and it should be two-way communication.
\end{abstract}

Key-words: Attitude, Contraceptives, Knowledge, Practice, Population growth, Unsustainable population

\section{INTRODUCTION}

Awareness, attitude and understanding of the responsibilities of the residents of a nation towards their land constitute the heart of its feasible growth and development. Out of all the issues, which India is fighting in the current scenario, uncontrolled population growth is the most important limiting factor, which halts the

\section{How to cite this article}

Dawra S, Goyal S, Gupta MC. Knowledge, Attitude and Practices of Contraceptive Methods in Women of Reproductive Age Group in an Urban District of Haryana. SSR Inst. Int. J. Life Sci., 2020; 6(1): 2455-2461.

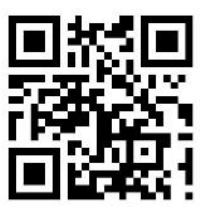

progressive development of the nation.

Family planning is the key to slowing unsustainable population growth that has multiple negative impacts on the economy, environment and maternal as well as infant health. Family planning refers to a conscious effort by a couple to limit or space the number of children; they have through the use of contraceptive methods ${ }^{[1]}$. WHO has defined family planning as giving a chance to society to determine the number of children and pregnancy spacing through contraceptive methods [2]. According to Tsehaye et al. ${ }^{[3]}$, maternal and infant mortality can be reduced by a minimum of $25 \%$ through appropriate family planning programs and birth spacing in developing countries. India was the first country in the 
world to implement a national population control programme in year 1952 but is still struggling to contain the baby boom ${ }^{[4]}$. India ranks $2^{\text {nd }}$ amongst the world's most populous countries with a birth rate of 19 births $/ 1,000$ population and is projected to be the world's most populous country by 2024 , surpassing the population of China ${ }^{[5]}$. Many efficacious methods of contraception, such as condoms, pills, diaphragms, IUDs, implant, male sterilization (vasectomy), female sterilization (tubectomy) are easily available. Despite these many alternatives, the incidence of unwanted pregnancies still remains high in many countries. According to Singh et al. ${ }^{[6]} 15.6$ million abortions (range 14.1 million-17.3 million) took place in India in 2015, giving an abortion rate of $47.0(42 \cdot 2-52 \cdot 1)$ per 1000 women aged 15-49 years. These findings give an impression that the majority of women are unaware of the need for contraception and many have still not identified an ideal method of contraception, which fits their lifestyle and meets their personal requirements ${ }^{[7]}$. Increased usage of contraceptives during the postpartum period and spacing a new pregnancy to at least 3 years after the previous birth substantially reduces the rates of maternal and infant mortality by preventing unwanted pregnancies ${ }^{[8]}$. According to Conde et al. ${ }^{[9]}$, there is an increased risk of maternal morbidity and complications in pregnancies with women with short birth intervals (<24 months). Acceptance and adoption of contraceptive practices can control unwanted pregnancies, thus reducing the potential complications related to them, as well as have a significant positive impact on women's general health and quality of life due to their physical and psychological growth ${ }^{[10]}$. The perception of family planning by women is also dependent on good knowledge and has a great impact on their attitudes and practices ${ }^{[11]}$. Women could potentially be benefiting from increased awareness and guidance on contraceptive practices and can be assured that their chosen method is the best suitable method according to their individual needs. Most of the reproductive age women have little or incorrect information about family planning methods. Even, when they are aware of some names of contraceptives, they don't know where to avail them or how to use them. In order to follow old traditions and misleading information that is being passed in their family for generations, women tend to have negative attitudes about their health problems, newer techniques and the importance of family planning ${ }^{[12]}$. This study was conducted with an objective to assess the knowledge, attitude and practices (KAP) of family planning methods and various socio-demographic parameters and enhance the contraceptive practices among the women in an urban area of Haryana, so as to have a positive impact on their beliefs regarding the use of contraceptive methods.

\section{MATERIALS AND METHODS}

Study design and participants- It was a cross-sectional study conducted in the area of Rohtak district, Haryana by the Department of Pharmacology, Pt. B.D. Sharma, PGIMS, Rohtak, India from July 2019 to September 2019. The study participants were enrolled by conducting a survey of both married and unmarried women attending the Outpatient Departments (OPD) in PGIMS Rohtak, Haryana. Prior consent was obtained from the participants before the interview.

Inclusion Criteria- Women in the reproductive age group residing in that area.

Exclusion Criteria- Women, who refused to participate in the study.

Study design- A pre-tested; pre-designed questionnaire was used by the investigator to interview the selected participants. A total of 260 women of reproductive age group (16-50 years) were enrolled in the study and asked about the questions included in the study. The questionnaire had two domains, the first domain consisted of 7 demographic questions and second domain consisted of 12 questions that assessed their knowledge, attitude and practices of contraception. The questionnaire included information regarding age, education, occupation, religion, knowledge, attitude, practices towards various family planning methods etc. The questionnaire was first validated by conducting a pilot study on 30 women and the required changes were made in the proforma.

Statistical Analysis: The collected data was entered into an excel sheet and it was analyzed using percentage and test of proportions. The responses to the schedule by each participant were entered into an excel sheet. The data was tabulated and statistical analysis done by using SPSS (Statistical Package for the Social Sciences) software, version 23.0. This study was conducted to 
assess current levels of usage and awareness of different forms of contraception, reasons for choosing or changing methods and sources of information.

RESULTS: As depicted in Table 1, mean age of the study participants was 26.3 years. The most frequent age group was 25 to 29 years (44.61\%). The majority of the participants were literate $(88.85 \%)$ and the rest of them (11.15\%) were illiterate. Total $81.53 \%$ of the women belonged to the Hindu religion. Among these women, $81.15 \%$ of the women were married and $18.84 \%$ of them were unmarried. Most of the participants were housewives (45.76\%) and working (40\%) and around $14.23 \%$ of the women were students.

Table 1: Demographic characteristics of the study population

\begin{tabular}{cc}
\hline Characteristics & $\mathbf{n}(\%)$ \\
\hline \multicolumn{2}{c}{ Age (years) } \\
\hline $20-24$ & $14(5.38)$ \\
$25-29$ & $83(31.92)$ \\
$30-34$ & $116(44.61)$ \\
$35-39$ & $34(13.07)$ \\
$\geq 40$ & $4(1.53)$ \\
& $9(3.46)$
\end{tabular}

\section{Education status}

$\begin{array}{lc}\text { Literate } & 231(88.85) \\ \text { Illiterate } & 29(11.15) \\ \text { Religion } & \\ \text { Hindu } & 212(81.53) \\ \text { Muslim } & 31(11.92) \\ \text { Sikh } & 11(4.23) \\ \text { Christian } & 6(2.30) \\ \text { Marital status } & \\ \text { Married } & 211(81.15) \\ \text { Unmarried } & 49(18.84) \\ \text { Occupation } & \\ \text { Housewife } & 119(45.76) \\ \text { Working } & 104(40) \\ \text { Student } & 37(14.23)\end{array}$

Table 2 shows that the awareness of participants regarding contraceptive methods. Total $97.69 \%$ of women were aware of contraceptive practices and family planning and $2.30 \%$ women were unawareness about contraceptive practices.
Table 2: Awareness of contraceptive methods

\begin{tabular}{cc}
\hline $\begin{array}{c}\text { Awareness about } \\
\text { contraception }\end{array}$ & $\mathbf{n ( \% )}$ \\
\hline Yes & $254(97.69)$ \\
No & $6(2.30)$
\end{tabular}

Table 3 shows the knowledge and practices of various contraceptive methods. Most of the women were aware of male condoms (94.23\%) and $66.92 \%, 64.23 \%, 51.15 \%$ of the women knew about the pills, tubectomy and intrauterine devices respectively. 50\%, $44.23 \%$ and $30 \%$ of the women were aware of calendar method, lactation amenorrhea and coitus interruptus, respectively. Women were less aware of the implants, diaphragms and female condoms. Also, $71.53 \%$ of women had gained knowledge regarding contraception through TV, radio or newspapers, $58.07 \%$ of women had gained knowledge through health workers and $53.07 \%$ of women knew about contraceptive methods through family or friends. Total $80.76 \%$ of the women availed the contraceptives in pharmacies, $67.30 \%$ through hospitals and around $23.46 \%$ through health workers.

Table 3: Awareness regarding various contraceptive methods

\begin{tabular}{cc}
\hline Methods & Awareness $\mathbf{n}(\%)$ \\
\hline Lactation amenorrhoea & $115(44.23)$ \\
Calendar method & $130(50)$ \\
Coitus interruptus & $78(30)$ \\
Male condoms & $245(94.23)$ \\
Female condoms & $51(19.61)$ \\
Pills & $174(66.92)$ \\
Diaphragms & $30(11.53)$ \\
Intrauterine devices & $133(51.15)$ \\
(Cu-T) & $40(15.38)$ \\
Implants & $93(35.67)$ \\
Vasectomy & $167(64.23)$ \\
Tubectomy & \\
Source & $186(71.53)$ \\
TV/ Radio/Newspaper & $151(58.07)$ \\
Health worker & $138(53.07)$ \\
Family/Friends & \\
Access & $175(67.30)$ \\
Hospitals & $61(23.46)$ \\
Health-workers & $210(80.76)$ \\
Pharmacies &
\end{tabular}


As depicted in Table 4, 92.30\% of women believed that using contraception was beneficial, $73.07 \%$ of women encouraged their family members to support contraception, $33.07 \%$ of women were embarrassed, while buying or asking about contraception, $17.69 \%$ of women had difficulty in availing contraceptives.
As depicted in Fig. 1, male condoms were the most common method of contraception practiced by almost $38.07 \%$ of women, followed by pills used by $24.61 \%$ of women and IUDs by $13.84 \%$. Implants, diaphragms, female condoms were the least practiced methods of contraception.

Table 4: Attitude regarding contraceptives

Attitude regarding contraceptives

Contraception is beneficial

Feel embarrassment in asking about contraceptive

Difficulty in availing contraceptives

Encourage family members to use contraception n(\%)

$240(92.30 \%)$

86(33.07)

46(17.69)

190(73.07)

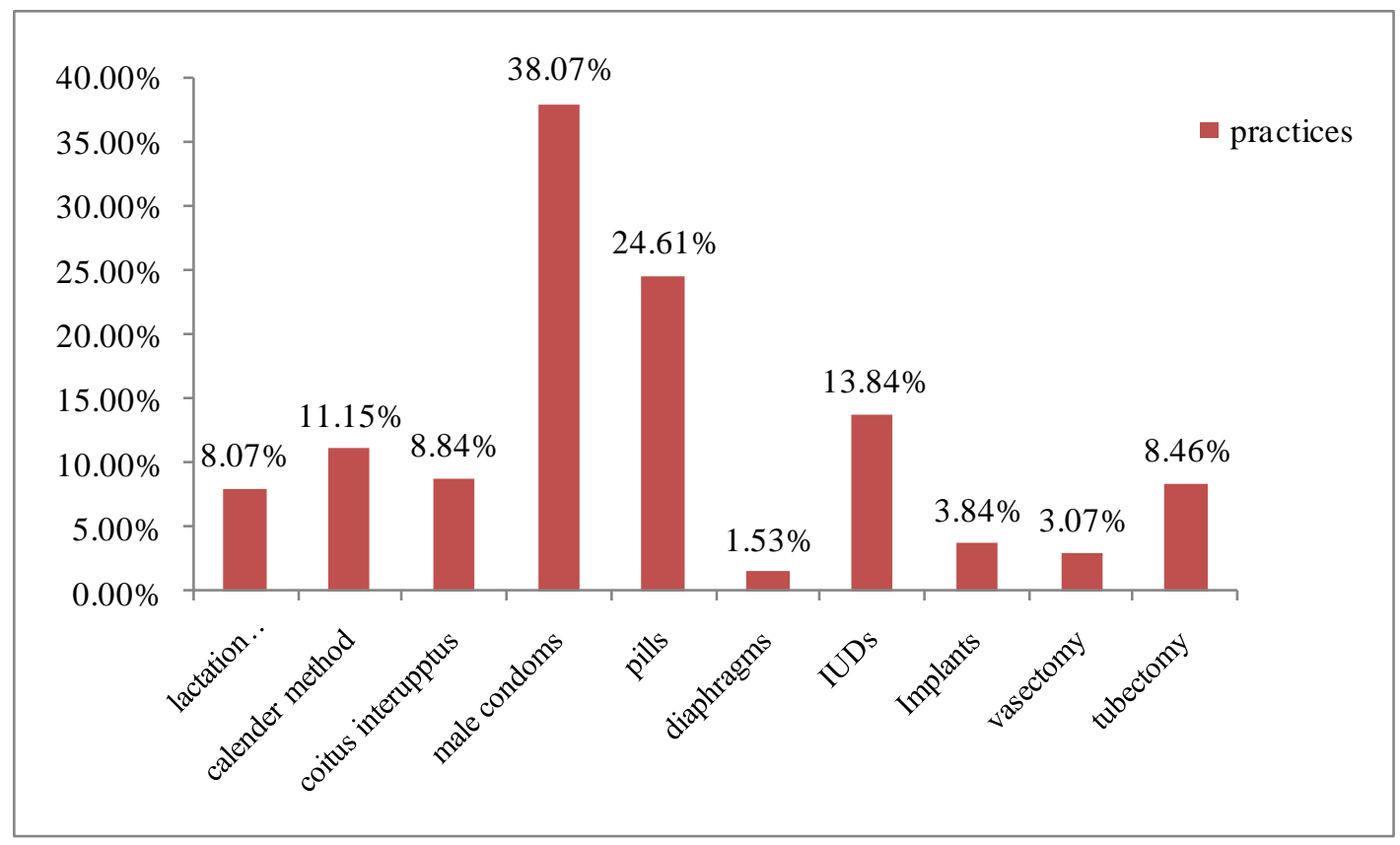

Fig. 1: Practice of contraceptives

As depicted in Table 5, most common side effect due to contraceptive methods was weight gain observed in $13.07 \%$ of women followed by bleeding (9.23\%), acne (8.84\%) and nausea (8.46\%).

As depicted in Table 6, $16.15 \%$ of women are not using any contraception. Out of them, 3.84\% of participants did not use any contraception because they have no proper information or they want to conceive (4.61\%) and $7.69 \%$ were opposed by family.
Table 5: Adverse effects of contraceptives

\begin{tabular}{cc}
\hline $\begin{array}{c}\text { Side effects experienced } \\
\text { due to contraception }\end{array}$ & $\mathrm{n}(\%)$ \\
\hline Weight gain & $34(13.07)$ \\
Bleeding & $24(9.23)$ \\
Nausea & $22(8.46)$ \\
Infection & $4(1.53)$ \\
Acne & $23(8.84)$ \\
\hline
\end{tabular}


Table 6: Reasons for not using any contraception

\begin{tabular}{lc}
\hline & $\mathbf{n}(\%)$ \\
\hline $\begin{array}{l}\text { Women not using any } \\
\text { Reasons }\end{array}$ & $42(16.15)$ \\
Want to get pregnant & $\mathbf{n}(\%)$ \\
No proper information & $12(4.61)$ \\
Family opposes & $10(3.84)$ \\
\hline
\end{tabular}

As depicted in Table 7, the majority of the working women and students have heard of at least one family planning method and almost $90 \%$ thought that using contraception is beneficial. Students and housewives were almost embarrassed at the same level, whereas working women were least embarrassed (18.26\%) regarding the discussion of contraception. More than $70 \%$ of working women and students believed in encouraging their family members regarding contraception, followed by housewives.

Table 7: Knowledge, attitude and practices of women according to their occupation

\begin{tabular}{|c|c|c|c|}
\hline & $\begin{array}{c}\text { Housewives } \\
\text { (n =119) }\end{array}$ & $\begin{array}{l}\text { Working } \\
\text { ( } n=104)\end{array}$ & $\begin{array}{c}\text { Students } \\
(n=37)\end{array}$ \\
\hline $\begin{array}{c}\text { Heard of } \\
\text { contraception }\end{array}$ & $113(94.95 \%)$ & $104(100 \%)$ & $37(100 \%)$ \\
\hline $\begin{array}{l}\text { Contraception } \\
\text { is beneficial }\end{array}$ & $108(90.75 \%)$ & 99(95.19\%) & $33(89.18 \%)$ \\
\hline $\begin{array}{c}\text { Feel } \\
\text { embarrassment } \\
\text { in asking about } \\
\text { contraceptive }\end{array}$ & $51(42.85 \%)$ & $19(18.26 \%)$ & $16(43.24 \%)$ \\
\hline $\begin{array}{c}\text { Encourage } \\
\text { family members } \\
\text { to use } \\
\text { contraception }\end{array}$ & $82(68.90 \%)$ & $81(77.88 \%)$ & $27(72.97 \%)$ \\
\hline
\end{tabular}

\section{DISCUSSION}

This study evaluated the data of 260 participants, most of them (44.61\%) were in the age group of $25-29$ years. $88.84 \%$ of the participants were literate, $81.15 \%$ of the women were married and $81.53 \%$ of the women belonged to the Hindu religion. Most of the participants were housewives (45.61\%) and working (40\%) and around $14.23 \%$ of the women were students. According to NFHS-4 around $99 \%$ of women in Haryana had knowledge regarding any one of the contraceptive methods ${ }^{[13]}$. According to this study, around $97.69 \%$ of women had heard of contraception. In the present study, the most common contraceptive used was condom (38.07\%), followed by pills (24.61\%) and IUDs (13.64\%). Implants, diaphragms, female condoms are the least practiced methods of contraception which was also similar to the study by Kashyap and Prasad ${ }^{[14]}$ according to which most of the women were using male condoms (55\%) followed by oral contraceptive pills (OCPs) (26\%), intrauterine contraceptive device (13\%). According to the study of Nigar ${ }^{[15]}$ barrier method (condoms) was in practice by $26.8 \%$, pills in $5.6 \%$, Cu T users were $3.2 \%$ and $1.2 \%$ were using DMPA (Depo-Medroxyprogesterone Acetate) for contraception.

Due to their low cost, availability and convenience, oral pills and condoms are the most preferred contraceptive methods [16]. In this study, it was observed that the majority of women $(71.53 \%)$ had gained knowledge regarding contraception through $\mathrm{TV}$, radio or newspapers, followed by health workers and family or friends. This observation was also consistent with the study of Kashyap and Prasad ${ }^{[14]}$ according to which a major source of knowledge about family planning methods was mass media (54\%), health facility (42\%), followed by personal relations i.e. spouse, friends, and relatives (34\%), and magazines (21\%). In another study, most patients came to know about contraception from television, doctors and other healthcare giver [17]. According to Sharma and Valente ${ }^{[18]}$ women, who was exposed to Radio programmes had significantly discussed family planning with their spouse. In around $8 \%$ of women, it was observed that the reason for not using contraception was an opposition to the family or husband. In a study, it was observed that wives are more likely to use contraception if their husband approve of it, or couples discuss this topic which each other and plan accordingly Lasee and Becker [19]. According to Hemavarneshwari et al. ${ }^{[20]}$ around $7.2 \%$ of women were opposed by family members. In this study, it was observed that weight gain followed by bleeding $(9.23 \%)$, acne $(8.84 \%)$ and nausea $(8.46 \%)$ were the most common side effect associated with contraceptive methods. According to Thapa et al. ${ }^{[21]}$, commonest side effects were weight gain and menstrual irregularities 
followed by heavy bleeding $(20.5 \%)$ and amenorrhea (18.2\%). According to this study, most working women and students believed in encouraging their family members regarding contraception and were less embarrassed in asking about contraceptive practices, followed by housewives. It has been observed in various studies that more empowerment and education of women can change their attitude and beliefs regarding their safety, health promotion and could improve the use of contraceptives ${ }^{[21,22]}$. The adoption of Family planning is not just related to control the birth rate, it is also associated with programmes, policies, interventions, awareness, information and practices which provide all the individuals with the ability to understand and promote measures for better health outcomes [23]. Konkane et al. ${ }^{[24]}$ mentioned that encouragement and a good knowledge of healthcare workers, thus decreasing the fear of side effects and myths, and counseling of husbands are very important to improve the perspectives regarding contraceptive use among the population. The government needs to improve the education provided by family planning healthcare workers ${ }^{[25]}$.

\section{CONCLUSIONS}

Occupation and literacy are the utmost important factors for understanding of the concept of family planning in the population. Family members play an important role in supporting women for the adoption of family planning therefore the involvement of family members during the counseling sessions should be increased, thus limiting the myths and misbelieve regarding contraceptive practices.

Mass media and health workers played an important role in educating women, the internet can be used or social media can be utilized in this era to grab the attention of people regarding these practices.

\section{ACKNOWLEDGMENTS}

I gratefully acknowledge Dr. M.C. Gupta and Dr Sarita Goyal. Their ever available guidance, ability to pinpoint minor details, inexhaustible encouragement and efforts on suggesting, designing, advising and improving the study has enabled me to complete the study. I also acknowledge the participants for their support and patience.

\section{CONTRIBUTION OF AUTHORS}

Research concept- Dr. MC Gupta, Dr. Sarita Goyal, Dr. Sanjana Dawra

Research design- Dr. MC Gupta, Dr. Sarita Goyal, Dr. Sanjana Dawra

Supervision- Dr. MC Gupta, Dr. Sarita Goyal

Data collection- Dr. Sanjana Dawra

Data analysis and Interpretation- Dr. MC Gupta, Dr. Sarita Goyal, Dr. Sanjana Dawra

Literature search- Dr. MC Gupta, Dr. Sarita Goyal, Dr. Sanjana Dawra

Writing article- Dr. MC Gupta, Dr. Sarita Goyal, Dr. Sanjana Dawra

Critical review- Dr. MC Gupta, Dr. Sarita Goyal

Article editing- Dr. MC Gupta, Dr. Sarita Goyal

Final approval- Dr. MC Gupta, Dr. Sarita Goyal

\section{REFERENCES}

[1] Etefagh M, Shojaeizadeh D, Nori K, Sadeghi R. The effect of education to reduce depression rate in women with a history of tubal ligation surgery. J. Educ. Community Health, 2014; 1(1): 55-61.

[2] World health organization [Internet]. Family planning/contraception. (Accessed on 17/11/2019). Available from: http://who.int/en/news-room/factsheets/detail/family-planning-contraception, 2018.

[3] Tsehaye WT, Mengistu D, Birhanu E, Berhe KK. Assessment of preference and its determinant factors to ward modern contraceptive methods among women of reproductive age group in shire Indaselassie town, Northern Ethiopia. Int. J. Family Med., 2013; 2: 34-40.

[4] Renjhen P, Kumar A, Pattanshetty S, Sagir A, Minoli C. A study on knowledge, attitude and practice of contraception among college students in Sikkim, India. J. Gynecol. Assoc., 2010; 11: 78-81.

[5] United Nations Department of Economic and Social Affairs [Internet]. [Accessed on 17/11/2019]. World Population Prospects, 2017. Available from: https://www.un.org/development/desa/publications /world-population-prospects-the-2017-revision.html, 2017.

[6] Singh S, Shekhar C, Acharya R, Moore AM, Stillman $M$, et al. The incidence of abortion and unintended pregnancy in India in 2015. Lancet, 2018; 6: 111-18.

[7] Finer LB, Henshaw SK. Disparities in rates of unintended pregnancy in the United States, 1994 
and 2001. Perspect. Sex Reprod. Health, 2006; 38: 90-96.

[8] RVernon. Meeting the family planning needs of postpartum women. Stud. Fam. Plann., 2009; 40(3): 235-45.

[9] Conde AA, Belizán JM. Maternal morbidity and mortality associated with interpregnancy interval: cross sectional study. BMJ, 2000; 321(7271): 125559.

[10]Wiebe ER, Littman L, Kaczorowski J. Knowledge and attitudes about contraception and abortion in Canada, US, UK, France and Australia. Gynecol. Obstet., 2015; 5(9): 1-10.

[11]Aryretey R, Kotoh AM, Hindin MJ. Knowledge, perceptions and ever use of modern contraception among women in east district, Ghana. Afr. J. Reprod. Health, 2010; 14(4): 27-32.

[12]Johnson S, Pion C, Jennings V. Current methods and attitudes of women towards contraception in Europe and America. Reprod. Health, 2013; 10: 1-9.

[13]National Family Health Survey (NFHS-4), India, 201516: Haryana (Internet). (accessed on 17/11/2019). Available from: https://dhsprogram.com/pubs/pdf/ FR339/ FR339.pdf.

[14]Kashyap P, Prasad S. Assessing the knowledge, attitude and practice of contraception in semi-urban area in India: a qualitative assessment of contraceptive usage. IJMRHS, 2018; 7(10): 150-54.

[15]Nigar A. Contraceptive awareness, and practices among rural women in Lucknow. IJOGR, 2018; 5(4): 454-57.

[16]Schindler AE. Non-contraceptive benefits of oral hormonal contraceptives. I. J. E. M., 2013; 11: 41-47.

[17]Nath J, Islam F. A Study on the Knowledge, Attitude and Practice about Contraception in Postpartum Women of North India. IJSR, 2015; 4(12): 456-58.
[18]Sharma M, Valente T. Spousal communication and family planning adoption: effects of a radio drama serial in Nepal. Int. Fam. Plan. Perspect., 2002; 28 16-25.

[19]Lasee A, Becker S. Husband wife communication about family planning and contraceptive use in Kenya. Int. Fam. Plan. Perspect., 1997; 23(1): 15-20.

[20] Hemavarneshwari S, Mangala S, Subrahmanyam G. Knowledge and attitude towards family planning practices among non-acceptors in a rural area in Bangalore, India. Int. J. Res. Med. Sci., 2015; 3(12): 3611-13.

[21]Thapa P, Pokharel N, Shrestha M. Knowledge, Attitude and Practices of Contraception among the Married Women of Reproductive Age Group in Selected Wards of Dharan Sub-Metropolitan City. J. Contracept. Study, 2018; 3: 1-8.

[22] Shaikh B, Haran D, Hatcher J. Women's social position and health seeking behaviors: Is the healthcare system accessible and responsive in Pakistan?. Health Care Women. Int., 2008; 29: 9451059.

[23] Hajira S, Kishore K. Assessment of knowledge about contraceptive methods among Bangalore Urban Women. M. I. M. C., 2014; 1(9): 508-13.

[24]Kokane AM, Palanivel C, Mahajan PB, Nair K, Bipin BB. Assessment of knowledge and practice of contraception among antenatal cases attending ANC. Clinic. Indian J. Maternal Child Health, 2011; 13(4): 2-8.

[25]Ajong AB, Njotang PN, Yakum MN, Essi MJ, Essiben F, et al. Determinants of unmet need for family planning among women in urban Cameroon : a cross sectional survey in the Biyem-Assi Health District, Yaounde. BMC Women's Health, 2016; 16(4): 1-8. 